\title{
Knowing My Peers: Edentity - To Invite Peer Interaction and Social Learning
}

\author{
Hanna M. Olsson and Thomas Persson Slumpi \\ Computer and Systems Science, \\ Mid Sweden University, Östersund, Sweden \\ \{hanna.olsson, thomas.persson\} @miun. se
}

\begin{abstract}
Digital spaces designated for learning need to invite to social learning. Oftentimes, however, students express feelings of loneliness in their learning in online courses. Making the students more visible to each other is hence crucial. In this article we present a study of students' self-presentations. We find that they are rather unelaborated, and we propose an alternative solution to making students identities visible within the learning space. Our proposed solution is a separate system that can be plugged into any digital learning system: the edentity.
\end{abstract}

Keywords: Edentity, social learning, digital identity, awareness.

\section{Introduction}

Digital learning spaces (DLS) have become increasingly important in contemporary higher education and in some cases they present the sole environment in which education takes place. A challenge that has emerged related to DLSs is that the students to a greater extent are feeling alone and isolated [1]. Learning is as such a social activity, which takes place in-between people [2], thus loneliness and isolation do not promote learning. A solution is to support the students' effort in establishing a social learning setting and encourage them to interact. But interaction requires knowledge of whom one is interacting with [3]. We argue that a first step towards creating a social learning setting in which interaction is central is that the students reveal cues about their identity to others. Identity is in this article, inspired by Callero [4], viewed as a subjective self-representation; it is a dynamic, context-dependent, hierarchically organized complex. Hence, different types of self-presentations in DLSs should reveal important identity cues.

In this article we present empirical data on how learners present themselves in a DLS related two different courses in the Swedish higher education, and what influence the teacher might have on these self-presentations. Based on this data, we propose an alternative way to make learners identities explicit in DLSs, with the purpose to invite peer interaction and social learning. We hypothesize that this would lead to increased motivation, learner experience and learning outcome. 


\section{$2 \quad$ Method}

This research departs from the most fundamental principle in hermeneutics, the hermeneutic circle which illustrates the relationship between the whole and the parts, and the continuous movement between the two [5]. The identity communicated through the self-presentation is viewed as the whole while the different cues revealed are viewed as the parts. Our approach to hermeneutics can be argued to be senderoriented and has its base in the work of Schleiermacher [6]. The sender-orientation implies that we as researchers try to reconstruct the meaning (the identity) the writer of the self-presentation intended to communicate (through the cues in the selfpresentation). In this article the identification of identity cues, hence the parts, are in focus of our attention. In order to identify the cues we have applied what Bergsröm and Boréus [6] label content analysis. The basic principle of content analysis is to count different occurrences in a text [6]. We have read through the students' selfpresentation repeatedly and counted different identity cues. The count of cues will contribute with 1) indication what students seem to find important to communicate and 2) indication if there is a difference what is communicated if the self-presentation is an assignment or not, e.g. what role the teacher plays.

In this article we have analyzed the self-presentation in two different courses in Informatics at Mid Sweden University. Course A concerns searching and critically evaluating information on the web. Course B concerns the design and construction of usable websites. Additional information concerning the courses is summarized in Table 1:

Table 1. Information related to the studied courses

\begin{tabular}{lcc}
\hline & Course A & Course B \\
\hline Duration & 5 weeks & 5 weeks \\
Number of students enrolled & 36 & 48 \\
Age span & $21-67$ & $20-55$ \\
Median age & 31 & 35 \\
Self-presentation assignment on course & Yes & No \\
DLS & WebCT & WebCT \\
\hline
\end{tabular}

What should be added to the above is that WebCT offers a function where the students can create a profile. This profile is however very static in nature and rarely used by the students. Also, related to the assignment in course A, there was a short instruction of what the presentation could include such as background, interests, why are you taking this course, expectations on the course and experiences of problems regarding searching the Internet for information (subject of the course). For course B there was a discussion forum with the heading of "Presentations", and a message from the teacher to "make a short presentation of your-self". 


\section{Theoretical Bpackground and Related Research}

Theoretically this article draws on two different theoretical approaches to identity creation: identity theory and social identity theory. These approaches over lap to some extent and complement one another on others according to Hogg et al. [7]. Three distinct categories related to the creation of an identity can be identified: master statuses, role identities, and group memberships. Master statuses include for example race, ethnicity or sex, and overrides other statuses and sometime they override each other depending on the context [8]. In identity theory, identity is viewed as a structural unit consisting of hierarchically organized roles [4]. Those roles can be more or less salient, and the more salient a role is, the more relevance it is given [4]. It is also the case that relationships with others influence the salience of a role [4]. Thus, salient roles should get greater focus in self-presentations. Finally, in social identity theory the membership in different groups are emphasized as important in the construction of an identity [7]. Identity is the meeting point of the individual and the group/society [9]. Thus, it is influenced by both the individual and the social context. Learning in itself also contributes to the development of one's identity [9]. Hence, identities are very much intertwined in any (social) learning situation.

When it comes to communicating identity cues in online environments, the most basic identity cues communicated in online environments (a baseline) can be synthesised from the work of Rusman et al. [10] and Berlanga et al. [11] and is summarized in Table 2 below. Rusman et al. [10] also provide a more elaborate set of cues comprising in total of 157 different cues. Due to space limitations we cannot include the complete list.

Table 2. Baseline of identity cues (synthesis of Rusman et al. [10] and Belanga et al. [11])

\begin{tabular}{ll}
\hline & Identity cues \\
\hline Name (first and surname) & Pseudonym (alias/display name) \\
Personal description & Age/Date of birth \\
Reference to personal URL (blog, website, & Social network sites or communities \\
etc.) & participating in \\
Contact method & Location data (business/ private) \\
Occupation/ function/ position/role & Company/ organization/ employer \\
Education & Interests (private/ professional) \\
Languages (level, preferred language for & Testimonials (references, info from others \\
communication) & about person) \\
Number of contacts & Contact data (business/private) \\
Expertise & Intentions for participation \\
\hline
\end{tabular}

Besides research on identity cues, research on the relation between identities and online environments often concerns identification and often refers to management of digital identities. For example, Milikic et al. [12] indicate the importance of benefitting from and merging available identity cues from diverse sources through diverse systems and propose a technical solution for this. It is however not only a technical issue. The users need to be in control of their digital identity(-ies) in order to feel secure and confident to provide personal information as well. A way to achieve this is for example by embedding it in mobile devices [13]. Since the user always carries the device with them, it is seen as a natural extension of themselves [13]. 
Student profiles are discussed by for example Kear [1] as a mean to enhance the sense of presence (i.e. the extent to which the users perceive each other as real [14]). Also E-portfolios have been proposed as a way to mediate student identity both with administrative [15] and didactic/promotion [16] motives. However, e-portfolios have been criticized by Olsson [17] for not being a suitable way of representing one's identity since it is traditionally used for showcasing only one's abilities. However, identity expression is about much more than abilities, as shown in Table 2.

\section{$4 \quad$ Results}

The result of the conducted studies of the courses is as is summarized in Table 3.

Table 3. Cues identified in student self-presentations

\begin{tabular}{lcccc}
\hline & \multicolumn{2}{c}{ Course A } & \multicolumn{2}{c}{ Course B } \\
\hline & $\begin{array}{c}\text { Actual } \\
\text { numbers }\end{array}$ & Percent & Actual & Percent \\
numbers & \\
Total number of registered students & 36 & $100 \%$ & 48 & $100 \%$ \\
Number of presentations & 34 & $94 \%$ & 26 & $54 \%$ \\
Number of pres. receiving reply & 0 & $0 \%$ & 3 & $12 \%$ \\
& & & & \\
Name & 23 & $68 \%$ & 22 & $85 \%$ \\
Place of birth & 4 & $12 \%$ & 3 & $12 \%$ \\
Age & 20 & $59 \%$ & 18 & $69 \%$ \\
Occupation & 15 & $44 \%$ & 20 & $77 \%$ \\
City of residence & 17 & $50 \%$ & 24 & $92 \%$ \\
Family/Status & 10 & $29 \%$ & 17 & $65 \%$ \\
Parallel studies & 14 & $41 \%$ & 13 & $50 \%$ \\
Pre-knowledge & 19 & $56 \%$ & 11 & $42 \%$ \\
Interests & 15 & $44 \%$ & 11 & $42 \%$ \\
Expectations/Attitude in rel. to & 26 & $76 \%$ & 17 & $65 \%$ \\
class & & & & \\
Future aims & 4 & $12 \%$ & 4 & $15 \%$ \\
\hline
\end{tabular}

The key findings are that the identified 11 identity cues to a large extent overlap with the baseline cues in Table 2, with a few exceptions like "Place of birth" and "Future aims". However, the cues identified in the students' self-presentations also did not include several identity cues found in the baseline like for example "Reference to personal URL (blog, website, etc.)" or a "Photo" (some, but far from a majority of the students, in fact had included a photo in the profile function provided in WebCT).

\section{Discussion and Conclusions}

The identity cues communicated in the self-presentations that we have studied are rather limited and unelaborated. But a person's identity is a dynamic, context-dependent, 
hierarchically organized complex. Hence, an identity cannot be communicated by only a few cues. A minimum could be argued to be the cues in the baseline, but even these are perhaps too few. It might be the case that the baseline needs to be complemented with cues found in the extended set of cues identified by Rusman et al. [10]. The lack of several of the baseline identity cues might indicate that the students' self-presentations were not sufficiently elaborated to establish interaction based on them. An indication that making the self-presentation an assignment actually prevented the students to initiate any social interaction was that the students sparsely commented on someone else's presentation. The few times this happened were in course B. That it only occurred when the presentation was not mandatory could indicate a more casual attitude towards the presentation and that they then become more usable. When students do comment, it is regarding something they can relate to, and the impression is that they seem to grasp onto anything that gives a familiar feeling.

When it comes to the teacher's influence on the self-presentation, it did not seem to influence the content of the presentations whether the self-presentation was an assignment with instructions or not. The same cues where roughly included in both cases. The only influence the teacher seems to have had, was that the number of students making a self-presentation became higher (94\%) if it was an assignment compared to $(54 \%)$ if it was not. Hence, the teachers seem to rather easily be able to influence the quantity of presentations within a course by making an initial assignment but not the content or the quality of it.

Self-presentations in DLSs seem not to be an efficient way to communicate identity cues. There is a need for a tool that can help mediate the identity with all its complexity and thereby enhances learning, motivation and user experience. The identity cues along with the tool are what we label the edentity. We picture the edentity as a separate system, platform independent, completely student-owned and student-controlled. This private system can then be plugged into any digital learning space at choice. At the time of the initial plugging in (or later through settings) to another system, the student chooses what information to share in this specific other system. This could be facilitated through predefined sets.

Our work towards the edentity has only just started. Further research is first to establish what needs to be part of an edentity. This is crucial in order to make it easier for students to communicate their identity in digital learning spaces and establish social relations with other students. Secondly it is about how the edentity should be associated with the student so it can be carried around at all times, become accessible for other students, but also be controlled by the student so he or she can increase or decrease the number of cues revealed to others.

\section{References}

1. Kear, K.: Social presence in online learning communities. In: The 7th International Conference on Networked Learning, Aalborg, Denmark (2010)

2. Vygotsky, L.S., Cole, M.: Mind in society: the development of higher psychological processes, p. 159 s. Harvard University Press, Cambridge (1978) 
3. Ke, F., Chávez, A., Causarano, P.-N.L., Causarano, A.: Identity presence and knowledge building: Joint emergence in online learning environments? International Journal of Computer-Supported Collaborative Learning 63, 349-370 (2011)

4. Callero, P.L.: Role-Identity Salience. Social Psychology Quarterly 483, 203-215 (1985)

5. Klein, H.K., Myers, M.D.: A Set of Principles for Conducting and Evaluating Interpretive Field Studies in Information Systems. MIS Quarterly 231, 67-93 (1999)

6. Bergström, G., Boréus, K.: Textens mening och makt: metodbok i samhällsvetenskaplig text- och diskursanalys, 2nd edn., p. 461 s. Studentlitteratur, Lund (2005)

7. Hogg, M.A., Terry, D.J., White, K.M.: A Tale of Two Theories: A Critical Comparison of Identity Theory with Social Identity Theory. Social Psychology Quarterly 584, 255-269 (1995)

8. Becker, H.S.: Outsiders: studies in the sociology of deviance, p. 179. Free press of Glencoe, London (1963)

9. Lave, J., Wenger, E.: Situated learning: legitimate peripheral participation. In: Learning in Doing, p. 138 s. Cambridge University Press, Cambridge (1991)

10. Rusman, E., Van Bruggen, J., Sloep, P., Valcke, M., Koper, R.: Can I trust you? - Personal profiling for a first impression of trustworthiness in virtual project teams (2010)

11. Berlanga, A.J., Bitter-Rijpkema, M., Brouns, F., Sloep, P.B., Fetter, S.: Personal profiles: enhancing social interaction in learning networks. International Journal of Web Based Communities 71, 66-82 (2011)

12. Milikić, N., Radulović, F., Devedžić, V.: Infrastructure for Exchanging Online Presence Data in Learning Applications. In: ERK Portorož (2011)

13. Satchell, C., Shanks, G., Howard, S., Murphy, J.: Identity crisis: user perspectives on multiplicity and control in federated identity management. Behaviour \& Information Technology 301, 51-62 (2011)

14. Gunawardena, C.N., Zittle, F.J.: Social presence as a predictor of satisfaction within a computer-mediated conferencing environment. American Journal of Distance Education 113, 8-26 (1997)

15. Ravet, S.: E-portfolio Interoperability Revised: Position Paper. In: Baumgartner, S.P., Bauer, Z.R. (eds.) The Potential of E-Portfolios in Higher Education, pp. 187-204. Studienverlag GmbH, Wien (2009)

16. Bauer, R.: Construction of One's Identity. A Student's View on the Potential of EPortfolios. In: Baumgartner, S.P., Bauer, Z.R. (eds.) The Potential of E-Portfolios in Higher Education, pp. 173-183. Studienverlag GmbH, Wien (2009)

17. Olsson, H.: Proposing Learner E-dentity to social presence in digital spaces for learning. In: Asproth, V. (ed.) Challenges for the future in an ICT Context ...for Stig, pp. 177-186. Mid Sweden University, Östersund (2011) 